\title{
On Editing, Improvement, and the Logic of Education
}

\author{
DEBORAH OSBERG, Editor-in-chief \\ University of Exeter (United Kingdom)
}

The scheme of a curriculum must . . select with the intention of improving the life we live in common so that the future shall be better than the past. (Dewey, 1930, p. 225)

This is my last editorial as editor-in-chief for Complicity. For the last four years I have worked hard with associate editors, Bill Doll and Donna Trueit, to try to overcome some of the limitations of scholarly publication (see Osberg, Doll \& Trueit, 2008). We have tried to enlarge the space of the possible ${ }^{1}$ (Osberg, 2009) for scholarly engagement in the "field" (if such exists) of complexity and education by attempting to create a space of engagement which explicitly provokes creative thinking and debate on the complexities of education (Osberg, 2009). This is not to say such provocations were missing from this journal before our term of editorship began, but that we took it as our mission, and duty, not simply to try to maintain the journal as it was (its operations and ethos), but to "improve" it by working with all those concerned with the journal to make it somehow "greater" than it was. The status of a scholarly journal is, after all, primarily dependent on the work/s of all those who contribute articles towards it.

Our dedication to "improving" the journal in this way is, perhaps, quite telling of our status as educators. Being an educator, can, after all, be seen as a professional life

\footnotetext{
${ }^{1}$ The phrase "enlarging the space of the possible," originating with Sumara \& Davis (1997), has become almost synonymous with the ethos of the journal, being referred to by Davis \& Phelps in their 2004 editorial (p.4.) and again by myself in my 2008 editorial (p. xx) which referenced that earlier quote, and several citations to these editorial references by authors contributing articles to this journal.
} 
devoted to "improving" the work ${ }^{2}$ of others-not directly, but by working with those others towards the "improvement" of their own productions-and the habit can be hard to shake. But outside of educational contexts, taking such a stance with (the work/s of) others-no matter how well meaning-can be seen as politically and ethically problematic in the sense of being arrogant, misguided, patronizing, condescending, and even disempowering. This is because the motivation to "improve" the work of others suggests not only that there is something "lacking" in the quality of the work of others (at least from the perspective of the one judging it), but also-and this is the more important point - that certain individuals are capable of rectifying this "lack" in the work of others. A question that has been foremost in my mind ever since taking on the editorship of this journal is: what gives anyone the authority and right to judge the work of others in this way? This question is pertinent not only in scholarly editing, where one "expert" judges another, but also in education, where teachers commonly assume the role of expert, as if it is their right to do so.

In our postmodernised, globalised world, however, where the legitimacy of overarching normative frameworks is permanently contested, there are a number of arguments to suggest that even within educational contexts, the idea that anyone has the right to guide others towards "correct" or "advanced" or in some other way "better" forms of knowledge and being, is highly problematic (see, e.g., Osberg \& Biesta, 2010). This, so the argument goes is partly because such guidance seems always to emanate from a particular normative framework ${ }^{3}$ which positions the student (who has yet to be included in that framework), relative to the teacher (who is already operating within that framework), as a "normative outsider" or deviant, and positions teachers (no matter how kindly or well-meaning) as despots whose primary goal is to replace the students' normative frameworks with their own. Furthermore, it positions education as "a practice of socialising people into a way of thinking/being/doing decided in advance, where those who do not manage to socialise or become socialised in the approved way are considered educational failures" (ibid, p. 604). But just because "improving" the work/s of others through educational interventions, both inside and outside of formalized educational contexts can be perceived to be politically and ethically problematic, I do not believe this means we should no longer engage in such action. My reasons for this are outlined in the next section.

\section{Improvement and the Expression of Agency}

If one accepts that the notion of "improvement" always implies the positive augmentation of what already exists (to improve something we cannot start from nothing), through the use of intelligent action towards the good, then it becomes possible to argue that it is the possibility of "improvement" that also allows us to express our authorship and agency. This is because, by working to improve something

\footnotetext{
2 "Work" is understood here as "an activity involving mental or physical effort done in order to achieve a purpose or result" (online dictionary definition)

${ }^{3}$ This can be any particular normative framework.
} 
already in existence, we are able to put something of ourselves-our own effort and intelligence-into the world that is. We can create, or author, something of our own which, in some way, transforms the world that is, into something other than it was, while also allowing the original to remain within the new that we produce. This understanding of "improvement" as the augmentation of the foundation (i.e., of what already exists), to bring about renewal (a new iteration) of what exists, has a clear connection to the concept of emergence, understood as something arising from a foundation which it transcends. " "Improvement," understood thus, gives us the opportunity to make our mark upon the world, as clearly as if we were to spray-paint our "tag" in a subway, for all to see. ${ }^{5}$ Through engaging with the "improvement" of the world that is, our actions are transcribed into and onto the world that is becoming: we have an effect on the world to-be, which enables us to feel our vitality as agency. After all, if we know that what we do has an effect on the world, then we know that our existence matters. But if an emergentist understanding of "improvement" is so key to understanding human agency, then it is worth taking a closer look at the way it plays out within education, which is supposed to be so closely associated with agency.

\section{Improvement, Agency and Education}

If we accept that an educator is a professional devoted "improving" the work of others (by working with those others on that work), then it is possible, also, to understand education as a practice which cannot take place except in common. It is a practice which makes it possible for the normative frame of student to meet the normative frame of the teacher. Although what takes place as a result of this meeting is supposed to be the "improvement" of the work of the student, and in this regard education must be understood as asymmetrical, ${ }^{6}$ the educator must also be able to experience her agency as an educator through understanding her actions to have "improved" the work of her student. One way of doing this, of course, is through assessment in terms of the educator's normative frame. This, however, usually entails asking the student to achieve a set of pre-determined outcomes that the student cannot feel comes from them or belongs to them. This deprives the student of agency as they are robbed of the opportunity to produce something of their own, to "improve" the world. One could argue that while the normative frame of student has indeed "met" the normative frame of the teacher, these frames have not "met" in the full sense of the word, as no communication between these frames of reference has taken place. They have merely brushed against each other. The solution, to this lack of communication, of course, is for the teacher to work with the student in a way that directs the student's own creativity,

\footnotetext{
${ }^{4}$ Some of these ideas originate from my reading of Hannah Arendt's (1969) article entitled "What is Authority?

${ }^{5}$ Although the tag, by some accounts, would not necessarily be an improvement to the wall of the subway, it is nevertheless a mark that is fairly enduring, which will affect those who gaze upon it, and through which agency is exercised.

${ }^{6}$ It is not expected that such interaction should bring about improvement in the work of the teacher although it is entirely possible that this may also take place.
} 
intelligence and normative framework towards "problems" that lie within the educators' normative frame. Because the problem comes from the educator (i.e., from the educators' normative frame or world), this presents the student with something other than what they would normally engage with, something other than what they would normally direct their energies, creativity and intelligence towards, something other than what they would normally ask of or do in the world. As such this enlarges possibilities for the student to express their agency (it askes them to do something other than, or additional to, what they would normally do). Not only does the educator achieve a sense of fulfillment/accomplishment/agency in witnessing that the student's work has indeed "improved" in the sense of it now being relevant also outside of the student's (narrower) normative frame. The student, too, is achieves a sense of fulfillment/accomplishment/agency in witnessing the fact that their own work has "improved" in the sense that it now has greater reach in the world. When the normative frame of the teacher meets and communicates with the normative frame of the student, this makes it possible for an "improvement" to take place that is neither wholly from the educator, nor wholly from the student, but in which the "improvement" (and sense of agency) is felt fully by both the educator and the student. Interestingly, the form this joint "improvement" will take, is also unpredictable from both perspectives (educator and student).

This understanding of the educational relation itself-which could perhaps be referred to as a "logic of education"7 rather than, e.g., a "logic of teaching" or a "logic of learning," both of which can be understood in terms of "improvement" taking place from one perspective only, i.e., "improvement" from the perspective of the teacher or "improvement" from the perspective of the learner (and usually with a predictable outcome) - suggests that the "logic of education" is far more fundamental to democratic living together life than is commonly believed. Indeed, it could be argued that it is only in the educational relation-i.e., through actions following the "logic of education"that democracy becomes possible. When the educational relation ceases, i.e., when teaching or learning takes place that is not necessarily educational (not allowing "improvement" from the perspective of all parties), democracy is nowhere be found for it furthers only the agency of one (one person, one group, one normative frame or point of view), and this often comes at the expense of the agency of others (other people, other groups, other normative frames or points of view).

Interestingly, and despite his insistence elsewhere that education is an asymmetrical relation, Dewey, in a quote in Democracy and Education, suggests that:

Not only is social life identical with communication, but all communication (and hence all genuine social life) is educative. To be a recipient of a communication is to have an enlarged and changed experience. One shares in what another has thought and felt and in so far, meagerly or amply, has his own attitude modified. Nor is the one who communicates left unaffected. . . . All communication is like art. It may fairly be said,

\footnotetext{
${ }^{7}$ I have used this term instead of the term "logic of emergence" (which I have sometimes used in my other articles) as I wish to draw a distinction between that form of emergence that arises from any relation, and that form of emergence arising from a very particular (democratic) kind of $a$ symmetrical relationship.
} 
therefore, that any social arrangement that remains vitally social, or vitally shared, is educative to those who participate in it. Only when it becomes cast in a mold and runs in a routine way does it lose its educative power. (1930, p. 6, my emphasis)

In this quote, Dewey implies that all communication is "educative" in the sense that all who participate in communication have their experience "enlarged and changed." While I agree with Dewey's observation that the outcome of all communication is mutually life changing, I would argue that that not all communication is "educative" if we understand education in terms of the "logic of education." With this logic, education is neither an outcome of communication, nor does it appear in any kind of communicative relationship. Education, rather should be interpreted as a very particular kind of assymetrical communicative relationship in which either

(i) as an educator, I engage with an other in such a way as to invite the other to bring her own intelligence and creativity to fruition as an agent working within my frame or

(ii) as a student I open myself to an other in such a way as to allow the other's frame of reference to suggest where (not how!) I might put to work my own intelligence and creativity, as an agent.

In either case, while the relationship is asymmetrical, the agency and intelligence of the other is treated as equal to my own, and the "outcome" of the educational relation-if it can be called such-is a single co-ordinated movement or "orchestration," which is ongoing as long as the relation continues (i.e., rather than two unconnected "improvements" in the form of "enlarged and changed experience" which each participant can separately "take away" from the conversation-which is not to say this cannot also take place in education, only that it is not what education is primarily about). If this "orchestration" can be understood as an "improvement," then it is an "improvement" that orchestrates difference... a creative bringing together of what does not "naturally" cohere.

In this issue of Complicity, although none of the authors who have contributed articles have addressed the theme of "improvement," nor necessarily framed their work in terms of the specifically educational reading of "improvement" I have provided here, these articles can nevertheless be interpreted through an educational reading of "improvement."

In the first research article, Olen Gunnlaugson touches on the idea of "improvement" through the notion of the "not-yet". He argues that a collective, conversational approach to learning - "presencing" - can open new spaces of being by facilitating a movement towards possibilities that are "not-yet embodied" "not-yet known" and "not-yet imagined." If I interpret him correctly, this is an argument for the "improvement" of the present in the absence of a particular normative framework chosen in advance. In response to this article, however, a collective of four authors (Nielsen, Biesta, Kieren and Zorn) question whether what comes into being through "presencing" is necessarily always going to be "worth anything" (p. 55) and hence will not necessarily have "educative value" (p. 57). 
Next up, Angus McMurtry examines the complexity of interdisciplinary knowing, drawing attention to the fact that there are two rather different approaches to this topic, one focusing on the complexity of the phenomena studied and the other the complexity of the socio-cultural dynamics of the "knowers." He argues that there is a need to bring these two frameworks into a productive conversation with each other- "thus providing a more open and productive space for interdisciplinary and interprofessional education and research" (p. 20) and that "complexivist and complexity-compatible ideas about learning and knowing can provide a way to integrate, without conflating, the two perspectives" (p. 20). In this regard, I believe McMurtry's project can be understood as one seeking to use complexity-based understandings of "improvement" to bring about an "improvement" in scholarship about the complexities of interdisciplinary learning. In response to this article, Ron Barnett argues that McMurtry's "two-dimensional" approach can be expanded (improved?) to a three-dimensional approach, which further complexifies the matter, introducing a "higher order of complexity" which Barnett refers to as "supercomplexity" where "the very terms in which complex systems are to be understood are liable to be disputed (and are often disputed)" (p. 64). Ultimately, what Barnett suggests, is that "the epistemology of interdisciplinarity has to give way to the matter of being and becoming among liquid knowledges" (p. 65). For me, this "giving way to being" can be interpreted as a giving way to the primacy of directionality as an ontology of "improvement."

Finally, in research article number 3, Don Gilstrap explores the phenomenon of social networking, arguing that these robust networks exhibit unique characteristics of "human ecological complexity" for which chaos and complexity theories provide a helpful analytic lens. His main point, however, is that chaos and complexity theories do not go far enough in helping us understand human ecological complexity in teaching and learning environments. This, so he argues, opens a challenges for educational researchers "to develop ontological and epistemological frameworks for creating and recreating curriculum theories that respond more readily to social networks" (p. 48). In this sense Gilstrap clearly calls for an "improvement" in educational thinking about human ecological complexity. In doing this he operates within what I have called a "logic of education" by inviting others to exercise their creativity and intelligence in this regard.

Responding to this article, John St. Julien argues that complexity theories pose a far greater challenge to education than Gilstrap gives them credit for, one which requires that we "get about the business of building a new intellectual framework within which to position educational research and practice" (p. 69). The point St. Julien is making, is that it is not simply that individual learners (understood as atoms) are now networked, but that the atomic project itself is challenged by complexity- and with this challenge the very concept of the individual (whether networked or not), that is so fundamental to modern educational theories, is radically undermined. St. Julien argues that this challenge calls for a fundamental rethink about what it means to educate. In this regard, St. Julien, like Gilstrap, operates within a "logic of education" by inviting others to exercise their creativity and intelligence in this regard, i.e., "to take up the task of constructing a more useful framework for educational research and practice" (p. 71). 
It is in this way that each of the research articles and the responses to them, can be read through the lens of some or other notion of "improvement." The educator in me therefore wants to invite all our readers to approach these articles with the notion of "improvement" in mind. Engaging with the articles in this way-i.e., through a lens (or curriculum) imposed by another (an educator)—so I believe, opens the possibility for something else to take place, something unexpectedly co-ordinated, where co-ordination did not exist before. I will not introduce the Semantic play articles and the Vignettes in this editorial, as Bill and Donna have done that in their section introductions. Nevertheless, I invite you to search for an educational reading of the notion of "improvement" in those articles too.

\section{Improvement, Agency and Editing}

Having argued for the importance of a particular understanding of the notion of "improvement" in education and having explained how this understanding can be sought even in articles that do not expressly seek to position themselves thus, let me now, again, return to the topic of editing, and the way in which Bill, Donna and I have dedicated ourselves to the task of improving this journal through our work, as editors, with those who have contributed articles.

I cannot deny that we have had an agenda. We have held certain beliefs about what a journal should be and how it should operate and this has shaped the kind of engagements we have had with our authors. This has meant the communicative relationship we have had with our authors has been asymmetrical. We have asked our authors to step onto our stage, and express their creativity, intelligence and agency in a way that is sensititive to our normative framework, our world. I hope we have done so in a way that has expressed the respect we feel for the creativity and intelligence of our authors, and the respect we feel for normative frames that are different from our own. Working in this way has stretched us immeasurably, but most of all-and I think I can speak for all three of us here-we do feel a very real sense of accomplishment in that the journal does indeed appear to have "improved" in the sense of attaining a broader "reach" through the conversations outside the "field" of complexity and education, which we have purposely and purposefully pursued. We hope our authors, too, feel a sense of fulfillment/accomplishment/agency in witnessing the greater reach of their own work "in conversation" with these other frames of reference. We hope, most of all that the relationship we have had with out authors has been felt as an educative relationship, that is, an asymmetrical relationship that is democratic and orientated towards orchestrated improvement.

As mentioned, this is now the end of my editorship, and Donna, too is retiring to the wings, where she will nevertheless continue to work with Bill in his role as associate editor. Working as a trio has sometimes been a trial, democracy is always difficult. But overall it has been a joy (to coin an expression oft used by Bill, which appears to have rubbed off on me). I have been enormously inspired through our efforts to create something together, and my experience working with these two wonderful people will 
remain with me for ever. Coming in to the position as editor-in-chief, is Michel AlhadeffJones, who, together with Bill (and others who will become members of the new editorial team) will no doubt construct their own agenda. I am confident that the journal is in good hands, and will continue to improve in the educational sense of the word.

\section{References}

Arendt, H. 1969. "What Is Authority:" in Between Past and Future. Cleveland and New York: World Publishing.

Davis, B. and Phelps, R. 2004. Complicity: An introduction and a welcome. Complicity: An International Journal of Complexity and Education, 1(1): 1-7.

Dewey, J. 1930. Democracy and Education, New York: Macmillan.

Osberg, D. 2008. The Logic of Emergence: An alternative conceptual space for theorizing critical education. Journal of the Canadian Association for Curriculum Studies 6(1):133-161

Osberg, D. 2009. "Enlarging the Space of the possible" around what it means to educate and be educated. Complicity. An International Journal of Complexity and Education, 6(1): iii-x.

Osberg, D. \& Biesta, G.J.J. 2010. The end/s of education: complexity and the conundrum of the inclusive educational curriculum. International Journal of Inclusive Education 14(6): 593-607.

Osberg, D., Doll, W.E \& Trueit, D. 2008. Gatekeepers of a complex field? Complicity. An International Journal of Complexity and Education, 5(1): iii-ix.

Sumara, D.J. \& Davis, B. 1997. Enlarging the space of the possible: Complexity, complicity, and action research practices. In Action Research as a Living Practice (pp. 299-312), edited by T. Carson and D.J. Sumara, New York: Peter Lang.

(C) Copyright 2011. The author, DEBORAH OSBERG, assigns to the University of Alberta and other educational and non-profit institutions a non-exclusive license to use this document for personal use and in courses of instruction provided that the article is used in full and this copyright statement is reproduced. The author also grants a non-exclusive license to the University of Alberta to publish this document in full on the World Wide Web, and for the document to be published on mirrors on the World Wide Web. Any other usage is prohibited without the express permission of the author. 